\title{
A SIMULINK MULTI-BAND POWER SYSTEM STABILIZER
}

\author{
Youssef A. Mobarak \\ Electric Engineering Department, High Institute of Energy, South \\ Valley University, Aswan, Egypt
}

(Received December 11, 2006 Accepted February24, 2007)

\begin{abstract}
A Multi-Band Power System Stabilizer (MB-PSS) is developed in this paper to get a moderate phase advance at all frequencies of interest in order to compensate for the inherent lag between the field excitation and the electrical torque induced to ensure robust oscillation damping. Its performance is compared with two conventional power system stabilizers (PSS) used to add damping to the rotor oscillations of the synchronous machine by controlling its excitation currents during disturbances. One of them is fed from acceleration power signal and called $\left(P_{a}-P S S\right)$ and the other is fed from speed deviation signal and called (dw-PSS). Digital time responses simulations of the nonlinear system performance during and after severe disturbances have proved effectiveness of the developed (MBPSS). The (MB-PSS) is found to be more effective than those with ( $d \omega$ $P S S)$ and $\left(P_{a}-P S S\right)$. The (MB-PSS) act very fast to follow transient system conditions and to restore its stability subsequent to severe disturbances.
\end{abstract}

KEY WORDS- Multi-Band Power System Stabilizer, Conventional Power System Stabilizer, Power System Stability, Oscillations Damping

\section{INTRODUCTION}

Power system synchronous stability is usually studied by a single mass turbinegenerator shaft [1-4] Machine infinite bus system or multi-machines power systems are usually used [3-6]. Power system oscillations can be classified in local oscillations between a unit and the rest of a generating station [4-7] in the order of $(0.8$ to 4.0$) \mathrm{Hz}$, interplant oscillations occur between two electrically close generation plants of the order (1.0 to 2.0) Hz [4] and inter-area oscillation between two major groups oscillations of frequency $(0.2$ to 0.8$) \mathrm{Hz}$ [1]. Those oscillations may lead to synchronous or angle or inertia instabilities [3]. Several cases hat recorded in literature [7-10]. Damping of those oscillations are reported to be done by power system stabilizers (PSS) [6]. Conventional PSS's are installed in many power plants. They are all based on single mass turbinegenerator and two motion equations one for the speed deviation $\mathrm{d}(\Delta \omega / \mathrm{dt})$ and the other for the rotor angle deviation $\mathrm{d}(\Delta \delta / \mathrm{dt})$, derived for one mass model.

In this study a new power system stabilizer is developed and called MultiBand Power System Stabilizer (MB-PSS). It is based on multi-frequency variables that stabilizer can obtain to cope with all low, intermediate, and high 
oscillations frequencies. The turbine-generator consists of five-mass representation in this analysis such as that used for with the Sub-Synchronous Resonance (SSR), but without series capacitor presence in the network. The MB-PSS is developed in such a manner that it can be capable of introducing moderate phase advance at all oscillations frequencies of interest in order to compensate for the inherent lag between the field excitation and the electrical torque [3]. Results showed superior results using such power system stabilizer

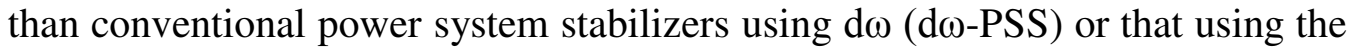
$\mathrm{dP}_{\mathrm{a}}\left(\mathrm{dP}_{\mathrm{a}}-\mathrm{PSS}\right)$, as input signals.

\section{STUDIED SYSTEM REPRESENTATION}

The studied system consists of two fully symmetrical areas linked together by two $230 \mathrm{kV}$ lines of $220 \mathrm{~km}$ length as shown in fig. (1). Despite its small size, it mimics very closely the behavior of typical systems in actual operation [1, 4]. Each area is equipped with two identical round rotor generators rated 20kV/900MVA. The synchronous machines have identical parameters, with inertias which are $\mathrm{H}=6.5 \mathrm{~s}$ in area $\# 1$ and $\mathrm{H}=6.175 \mathrm{~s}$ in area \#2, the parameters of the generators are given in Appendix (A).

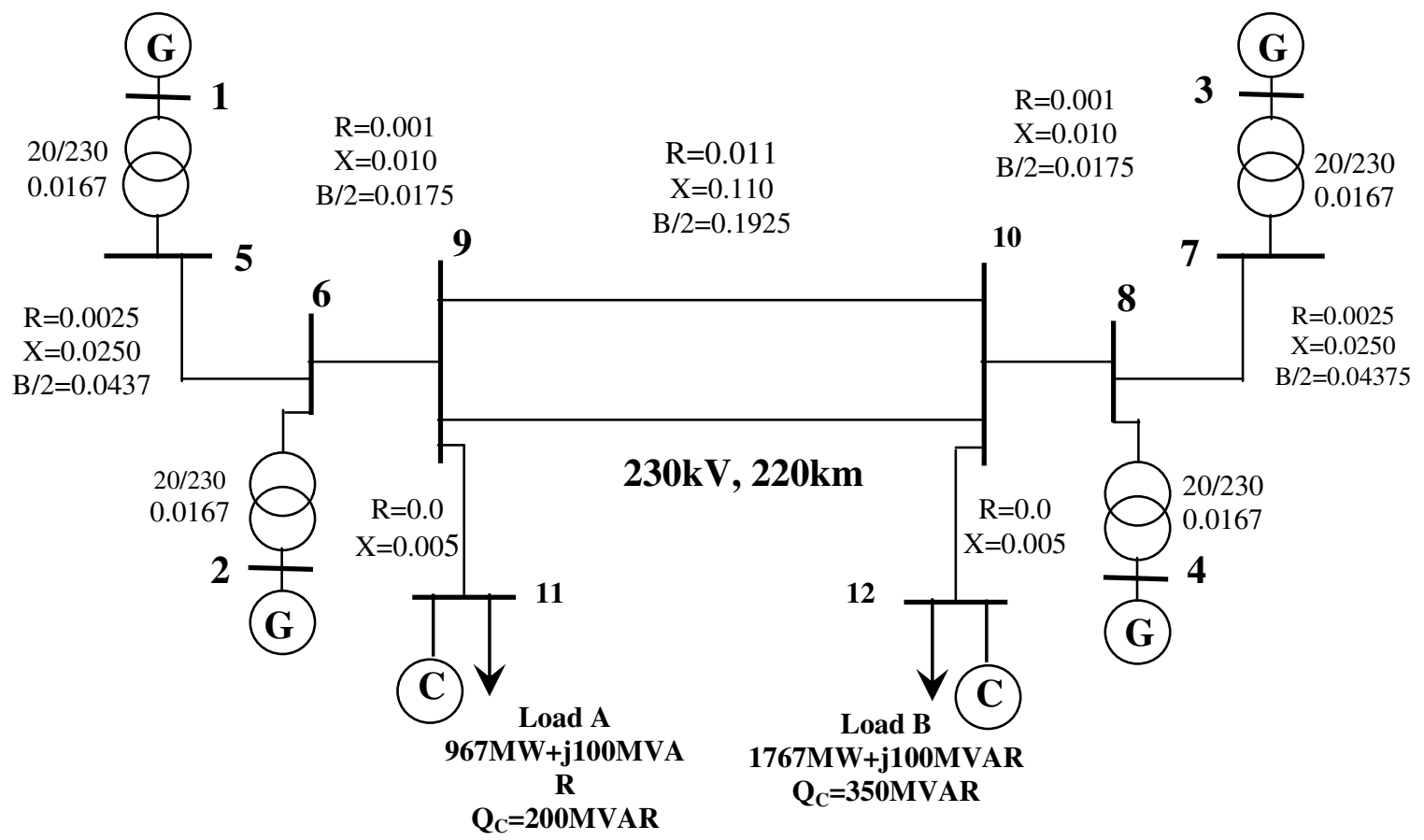

Fig. (1) The single line diagram of the studied system

Thermal plants having identical speed regulators are further assumed at all locations, in addition to fast static exciters with a gain 200. The load is represented as constant impedances and split fed between the areas in such a 
way that area \#1 exceeds $410 \mathrm{MW}$ over area \#2. Since the surge impedance loading of a single line is about 140MW [1], the system is somewhat stressed, even in steady-state.

Also, the IEEE benchmark for the SSR studies and particularly the torque amplification after a fault on a series-compensated power system [4] is used, but without series capacitor. It consists of a single generator connected to an infinite bus via two transmission lines. This system is completely different from that early presented in [1], using a single turbine-machine mass. A five masses system representing the generator's rotor and the turbine's, system is adopted in this study. Its data appear in Appendix A.

\section{SYSTEM COMPONENTS MODELING}

\subsection{Synchronous Machine Model:}

It models the dynamics of a three-phase round-rotor synchronous machine. The electrical part of the machine is represented by a sixth-order state-space model and the mechanical part is modeled by two motion equations. The model takes into account the dynamics of the stator, field, and damper windings. The equivalent circuit of the model is represented in the rotor reference frame (q-d frame). All rotor parameters and electrical quantities are viewed from the stator. They are identified by primed variables. The electrical model of the machine is shown in fig. (2). Its equations are given in Appendix B.
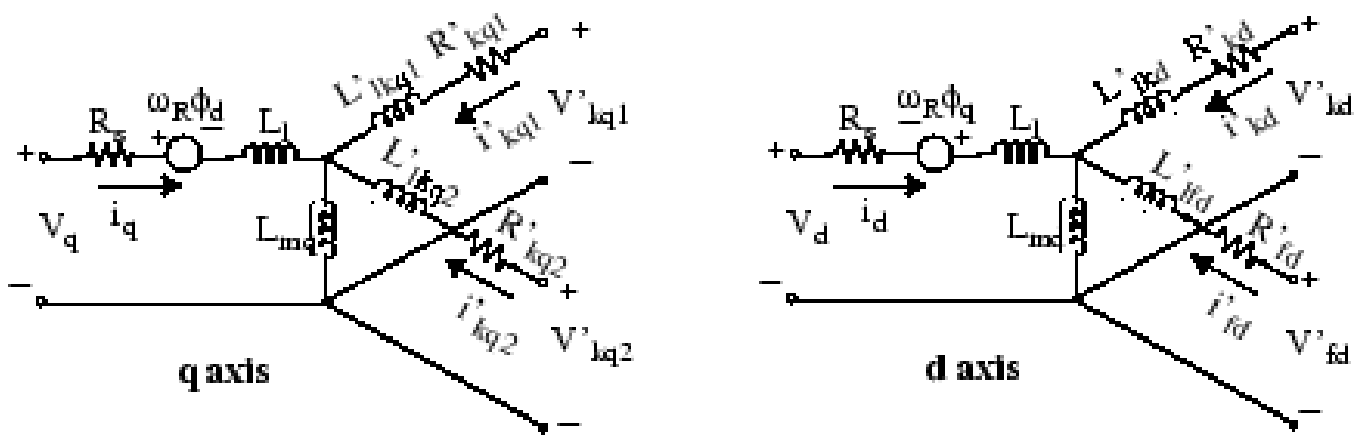

Fig. (2) The electrical model of the synchronous machine (q-d frame)

Magnetic saturation of stator and rotor iron is modeled by a nonlinear function (in this case a polynomial) using points on the no-load saturation curve. A 2-by-n matrix should be entered, where $\mathrm{n}$ is the number of points taken from the saturation curve. The first row of this matrix contains the values of the field currents, while the second row contains values of corresponding terminal voltages. The first point (first column of the matrix) must correspond to the 
point where the effect of saturation begins. Saturation is modeled by fitting a polynomial to the curve corresponding to the matrix of the entered points. The technique is illustrated in ref. \# [4].

\subsection{Excitation System Model:}

Figure (3) shows a developed simulink model for the excitation system given in ref. [1]. An excitation system for the synchronous machine to regulate its terminal voltage in generating mode is adopted and modeled by this simulink model. The model includes a Mux, low pass filter, lead-lag compensator, main regulator, proportional saturation, exciter, and damping feedback. Its output is field voltage $\mathrm{V}_{\mathrm{f}}$.

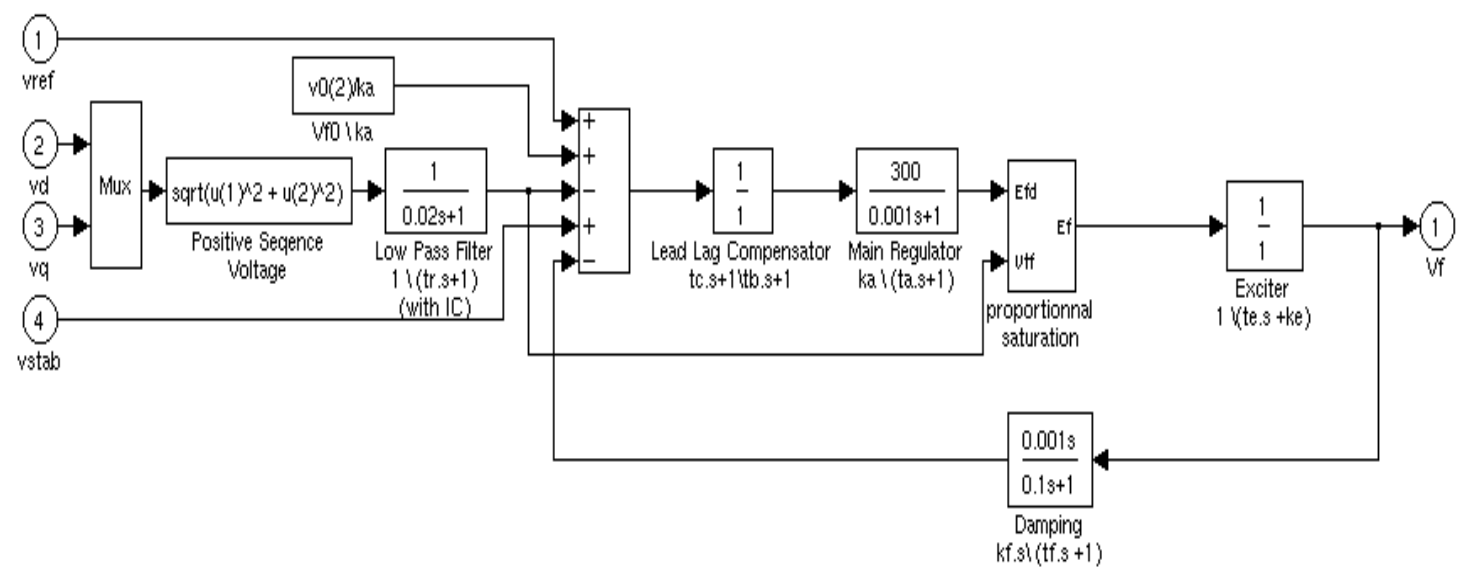

Fig. (3) Excitation system simulink model

The excitation system is implementing a dc exciter described in ref. [8], without the exciter's saturation function. The simulink basic elements that form the excitation systems are depicted in fig. (3), which represents the voltage regulator and the exciter. In that model, the exciter is represented by the following transfer function between the exciter voltage $V_{f}$ and the regulator's output $\mathrm{E}_{\mathrm{f}}$ is $\left(\mathrm{V}_{\mathrm{f}}=\left(1 /\left(\mathrm{k}_{\mathrm{e}}+\mathrm{t}_{\mathrm{e}} \mathrm{s}\right)\right)\right.$ ). A low-pass filter with time constant $\mathrm{t}_{\mathrm{r}}$, (in seconds), of the first-order is used to represent the stator terminal voltage transducer. The main regulator has a gain and time constant $k_{a}$ and $t_{a}$. The exciter is a gain $\mathrm{k}_{\mathrm{e}}$ and time constant $\mathrm{t}_{\mathrm{e}}$. Transient gain reduction time constants $t_{b}$, and $t_{c}$ of the first-order system represents the lead-lag compensator. Damping filter gain and time constant $\mathrm{k}_{\mathrm{f}}$ and $\mathrm{t}_{\mathrm{f}}$ of the first-order system representing the derivative feedback. Regulator output limits and gain $E_{f m i n}$ and $E_{f m a x}$ are imposed on the output of the voltage regulator. The upper limit can be constant and equal to $\mathrm{E}_{\mathrm{fmax}}$, or variable and equal to the rectified stator terminal voltage $\mathrm{V}_{\mathrm{tf}}$ times a proportional gain $\mathrm{k}_{\mathrm{p}}$. 


\subsection{Multi-Band Power System Stabilizer (MB-PSS):}

The need for effective damping of a wide range of electromechanical oscillations motivated the concept of the multi-band power system stabilizer (MB-PSS). As its name reveals, the MB-PSS structure is based on multiple working bands. The main idea of the MB-PSS is that three separate bands are used, respectively dedicated to the low, intermediate, and high frequency modes of oscillations. The low band is typically associated with the power system global mode, the intermediate band with the inter-area modes, and the high band with the local modes. Each of the three bands is made of a differential band-pass filter, gain, and limiter as shows fig. (4). The outputs of the three bands are summed and passed through a final limiter producing the stabilizer output $\mathrm{V}_{\text {stab }}$ (fig. (4)). This signal then modulates the set point of the generator voltage regulator so as to improve the damping of the electromechanical oscillations. The developed MB-PSS is represented by block diagram depicted in fig. (5). It is provided with built-in speed transducers whose parameters are to be adjusted according to user's specifications. Usually, a few of the lead-lag blocks should be used in MB-PSS's circuits.

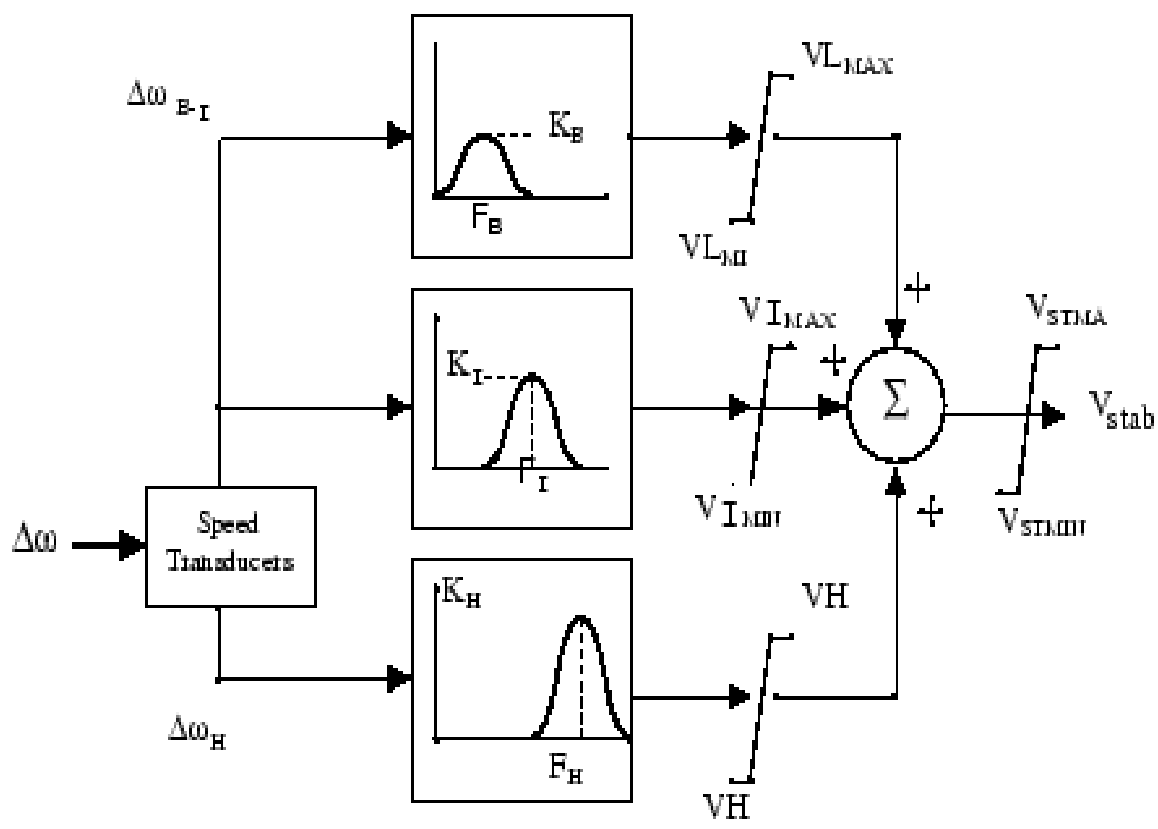

Fig. (4) Multi-band power system stabilizer (MB-PSS) conceptual representation 


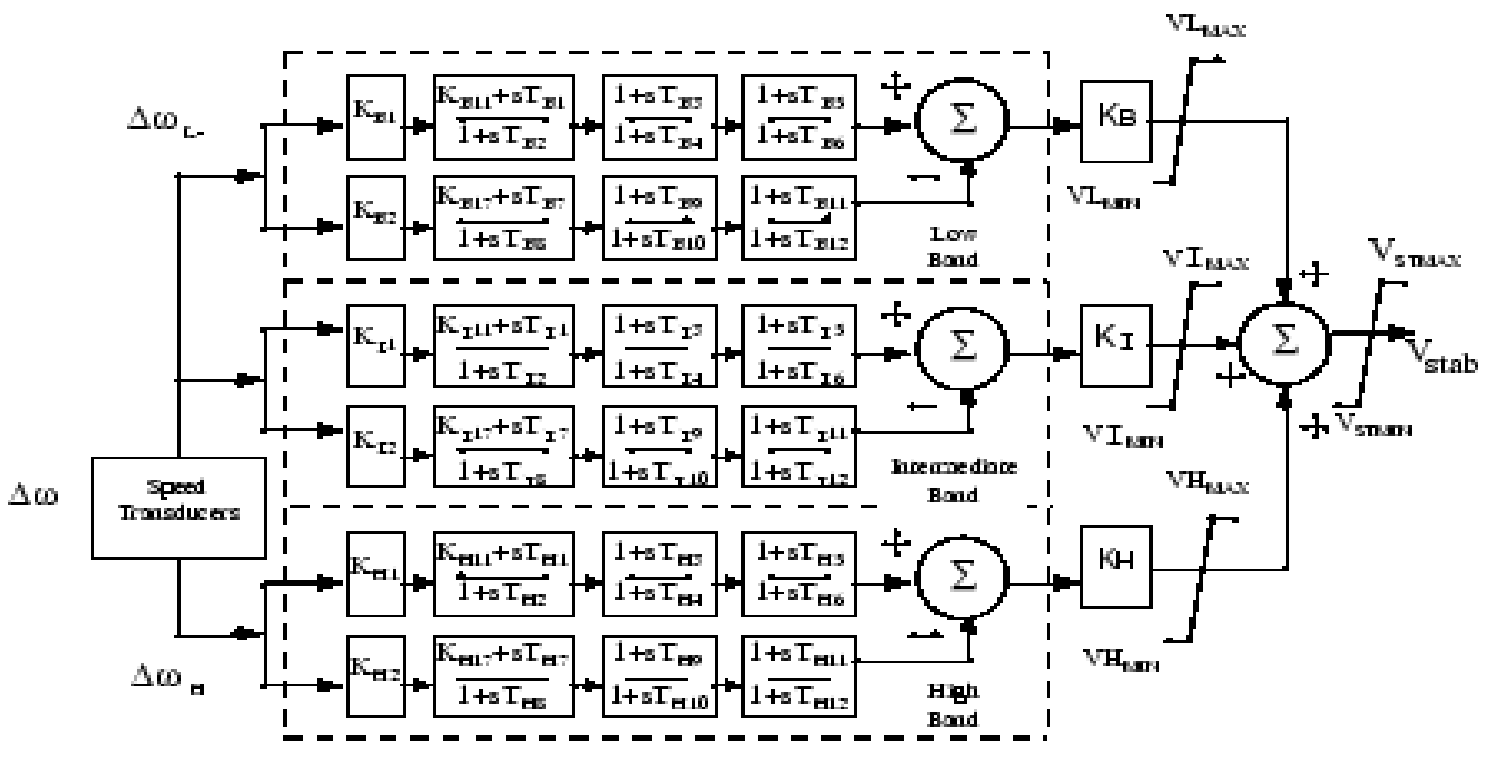

Fig. (5) Multi-band power system stabilizer (MB-PSS) internal specifications

\subsubsection{MB-PSS Tuning:}

Two different approaches are available to configure the settings during MBPSS tuning process:

(a) Simplified Settings: Only the first lead-lag block of each frequency band is used to tune the MB-PSS. The differential filters are assumed to be symmetrical band-pass filters respectively tuned at the center frequency $F_{B}, F_{I}$, and $F_{H}$ shown in fig. (4). The peak magnitude of the frequency responses given in fig. (4) can be adjusted independently through the three gains $\mathrm{K}_{\mathrm{E}}, \mathrm{K}_{\mathrm{I}}$, and $\mathrm{K}_{\mathrm{H}}$. Only six parameters are therefore required for a simplified tuning of the MB-PSS. They are $\mathrm{F}_{\mathrm{B}}, \mathrm{F}_{\mathrm{I}}, \mathrm{F}_{\mathrm{H}}, \mathrm{K}_{\mathrm{E}}, \mathrm{K}_{\mathrm{I}}$, and $\mathrm{K}_{\mathrm{H}}$. This method is adopted in this study.

(b) Detailed Settings: The designer is free to use all the flexibility to built into the MB-PSS structure to achieve nontrivial controller schemes and to tackle even the most constrained problem (for example, multi unit plant including an inter-machine mode, in addition to a local mode and multiple inter-area modes). In this case, all the time constants and gains appearing in (fig. 5) have to be specified.

\subsection{Conventional Power System Stabilizer (PSS):}

The conventional power system stabilizer is modeled by the following nonlinear system as shown in fig. (6), to ensure a robust damping, the conventional PSS should provide a moderate phase advance at frequencies of interest in order to compensate for the inherent lag between the field excitation and the electrical torque induced by the conventional PSS action. The model 
consists of a low-pass filter, a general gain, a washout high-pass filter, a phasecompensation system, and an output limiter. The general gain $\mathrm{K}$ determines the amount of damping produced by the stabilizer. The washout high-pass filter eliminates low frequencies that are present in the d $\omega$ signal and allows the PSS to respond only to speed changes. The phase-compensation system is represented by a cascade of two first-order lead-lag transfer functions used to compensate the phase lag between the excitation voltage and the electrical torque of the synchronous machine. Data for ( $\mathrm{d} \omega$-PSS) and $\left(\mathrm{dP}_{\mathrm{a}}-\mathrm{PSS}\right)$ are different, while the model is the same as show in fig. (6),

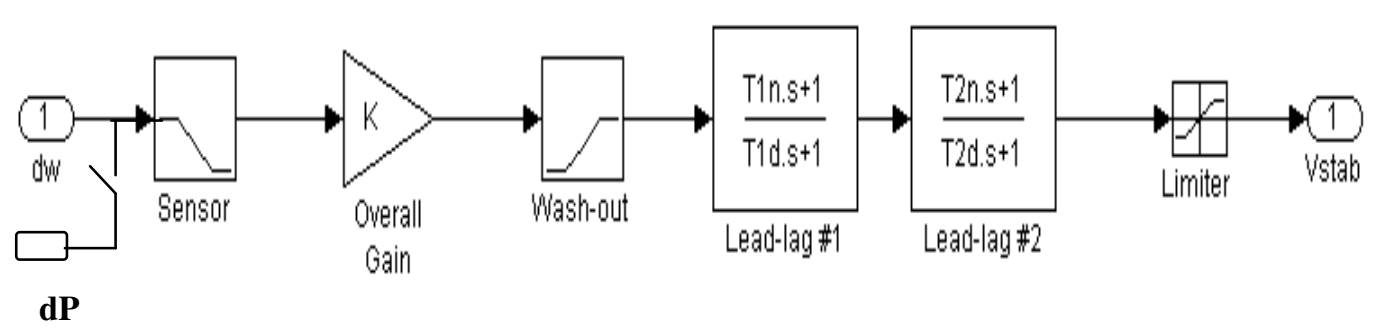

Fig. (6) Conventional (d $\omega$-PSS) and $\left(\mathrm{dP}_{\mathrm{a}}-\mathrm{PSS}\right)$ power system stabilizers simulink model

Input and output signals: Two types of signals can be used at the input, the synchronous machine speed deviation d $\omega$ signal (in p.u.), and the synchronous machine acceleration power $\mathrm{dP}_{\mathrm{a}}$. The output is the stabilization voltage (in p.u.) to connect to the $\mathrm{V}_{\text {stab }}$ input of the excitation system used to control the terminal voltage of the synchronous machine. The first one with speed signal deviation inputs called (d $\omega$-PSS) and the other with accelerate power signal input is called $\left(\mathrm{dP}_{\mathrm{a}}-\mathrm{PSS}\right)$. The parameters of the $(\mathrm{d} \omega-\mathrm{PSS})$ and $\left(\mathrm{dP}_{\mathrm{a}}-\mathrm{PSS}\right)$ are different from each other and given in Appendix (A).

\subsection{Steam Turbine and Governor Model:}

The steam turbine and governor implements a complete tandem-compound steam prime mover, including a speed governing system, a four-stage steam turbine, and a shaft with up to four masses as in fig. (7). Noting that the generator mass will be the fifth mass. The speed governing system consists of a proportional regulator, a speed relay, and a servomotor controlling the gate opening. Its simulink model shown in fig. (8). It is similar to these models proposed in [6]. 


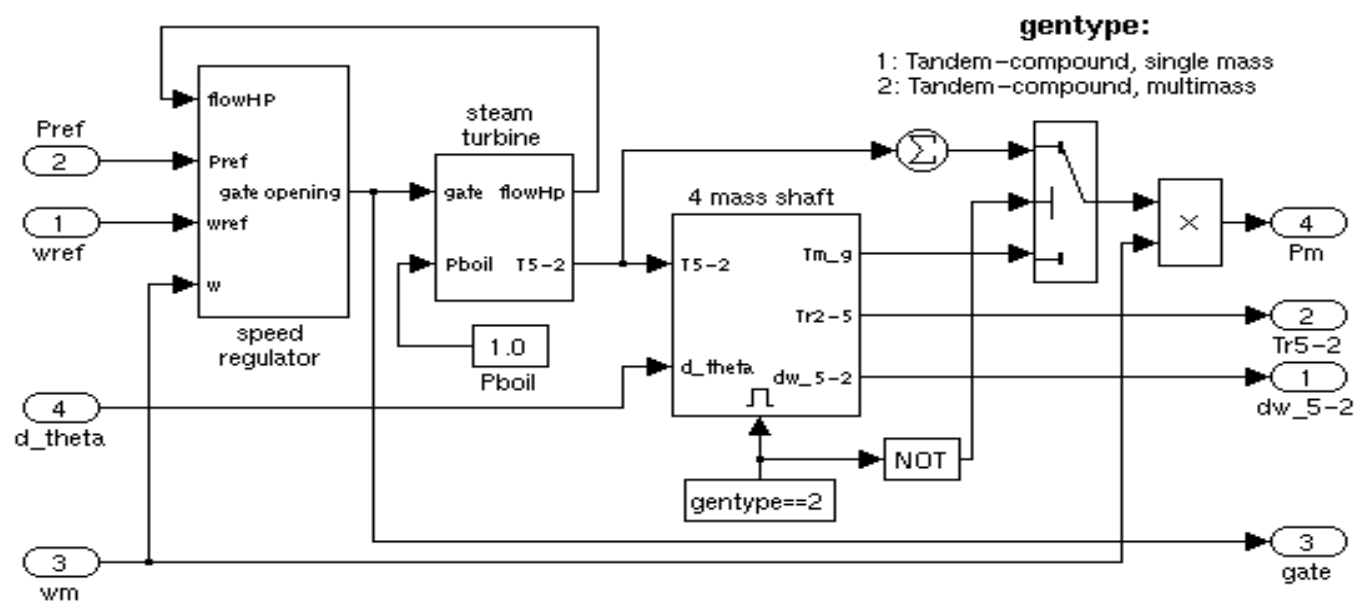

Fig. (7) A complete tandem-compound steam turbine and governor simulink model

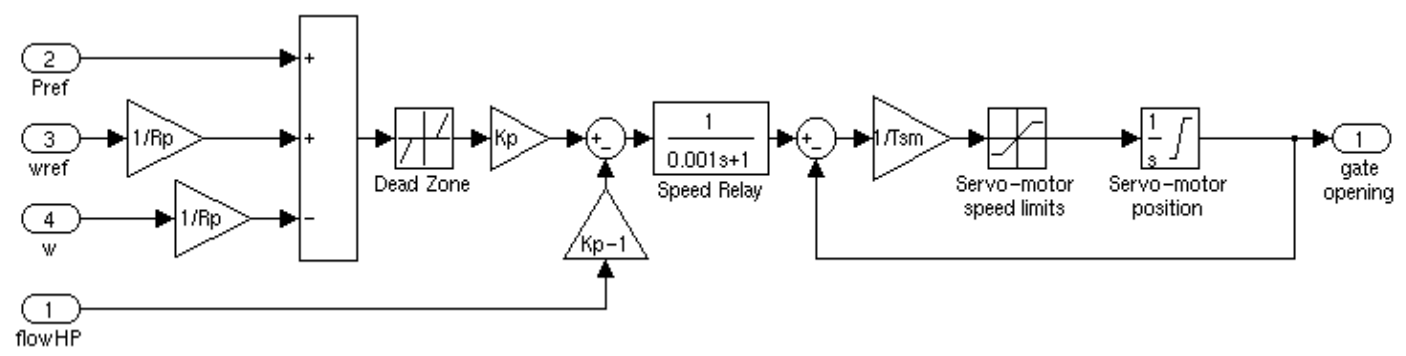

Fig. (8) Speed governing system simulink representation

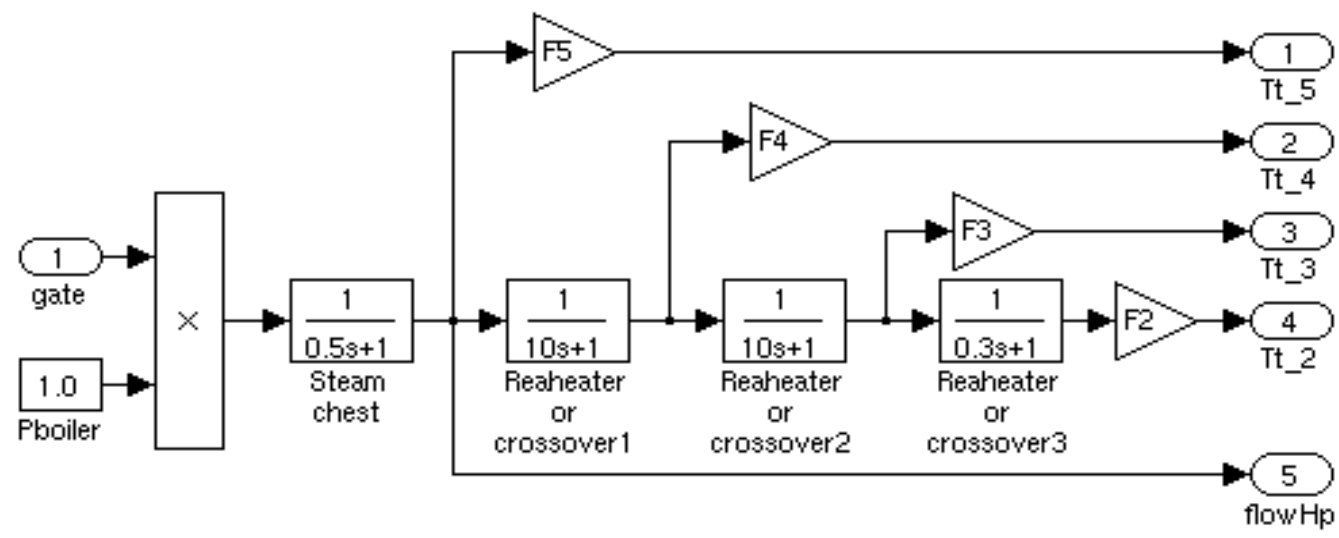

Fig. (9) Steam turbine with four stages simulink representation 
The simulink steam turbine model is given in fig. (9). It has four stages each modeled by a first-order transfer function, the generator mass will be the fifth mass and will be combined with the generator simulink model. The first stage represents the steam chest while the three other stages represent either reheaters or crossover piping. The boiler is not modeled and boiler pressure is kept constant at 1.0 p.u. Fractions $F_{2}$ to $F_{5}$ are used to distribute the turbine power to the various shaft stages. The shaft model with four-mass system is given in fig. (10), which is coupled to the fifth mass in the synchronous machine model for a total of five masses. The machine's mass is labeled mass $\# 1$. The mass in the steam turbine and governor block, which is closest to the machine's mass, is mass \#2, while the mass farthest from the machine is mass \#5. The shaft is characterized by mass inertias $H_{i}$, damping factors $D_{i}$, and rigidity coefficients $K_{i}, i=1,2,3,4,5$.

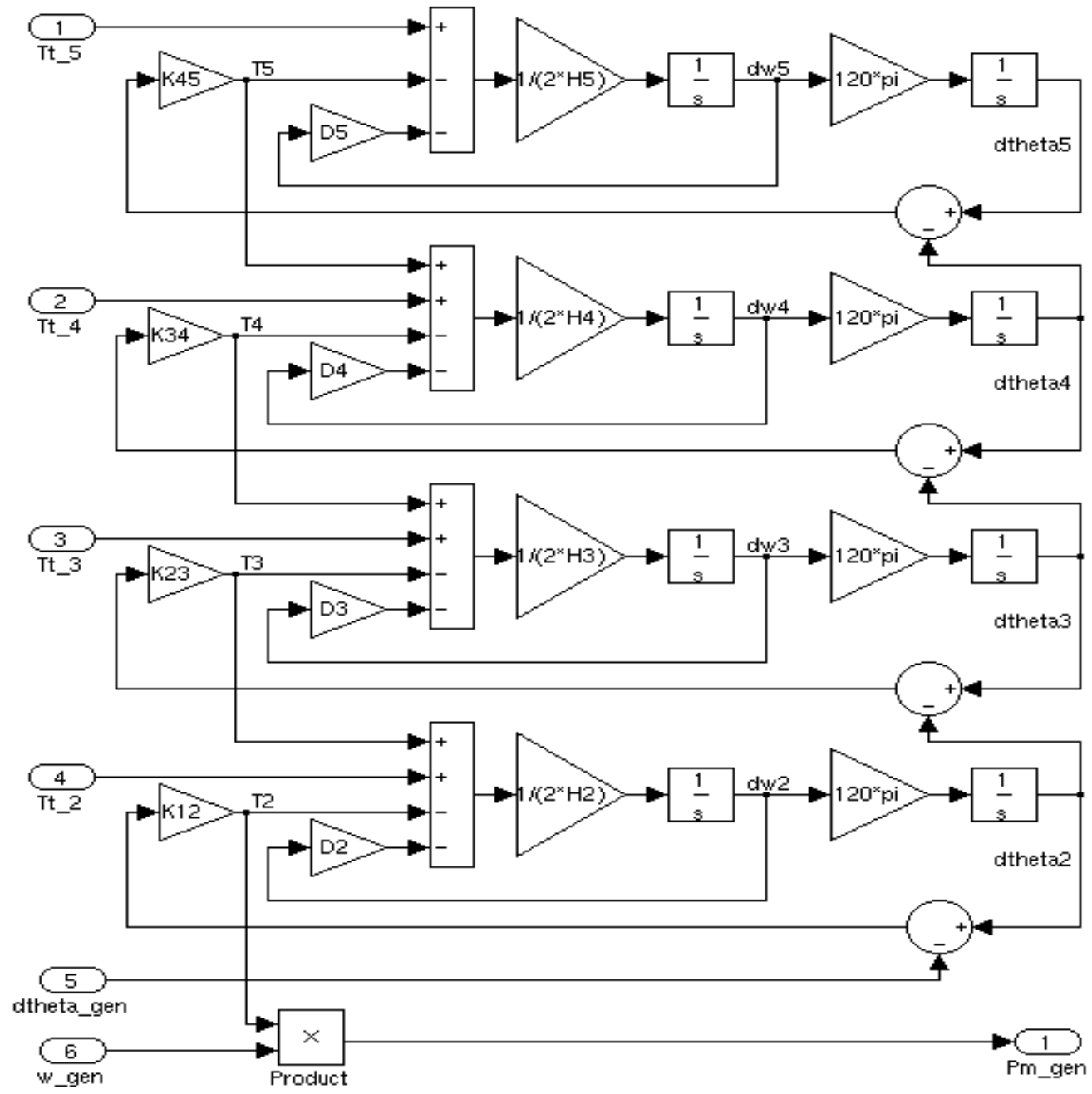

Fig. (10) Simulink shaft model with a four-mass system 


\section{RESULTS AND DISCUSSIONS}

The MB-PSS settings were adequate selected by varying the center frequency and gain of each band so as to achieve a nearly flat phase response between (0.1-5) Hz. The (d $\omega$-PSS) settings are selected from ref. \# [1], with two differences, the gain increases from 20 to 30 and addition of a transducer with 15-ms time constant. The MB-PSS phase is effectively flat around 20-40

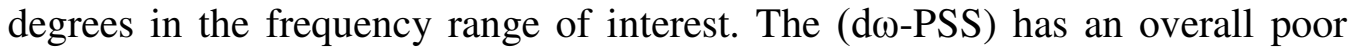
phase shape, especially around (1-2) Hz, which makes it unable to cope with faster local or intermachine modes in multi-unit power plants. By contrast, the $\left(\mathrm{dP}_{\mathrm{a}}-\mathrm{PSS}\right)$ has a good combination of strong gain and phase advance above 0.3 $\mathrm{Hz}$, although it is unpractical at low frequency, which actually has a destabilizing effect despite the rather small low-frequency gain.

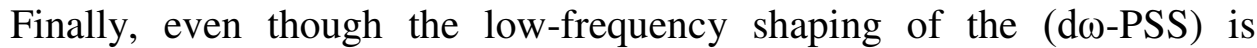
satisfactory in overall, its DC rejection (washout) is not efficient enough, providing five time less attenuation than the (MB-PSS).

\subsection{Load voltage profile analysis of the studied systems:}

Machines and load-flow initialization are selected to be slightly different from those in ref. \# [1], as the load voltage profile has improved to be closer to 1.0 per unit by installing 180MVAR more capacitors in each area. In addition, transmission and generation losses are varied depending on the detailed level in line and generator representation. Figure (11) shows the load voltage profile with and without the adopted reactive power compensation $\mathrm{Q}_{\mathrm{C}}$, performance of the rotor angle (delta), speed deviation $d \omega$, the terminal voltage $V_{t}$, the field excitation voltage $E_{f d}$, acceleration power $P_{a}$, and tie line power $P_{\text {tie }}$ in the two area system.

\subsection{Effects of system variables responses after voltage reference disturbance on Machine \#1:}

For an initial understanding of the network behavior, its open-loop responses (No-PSS) are simulated with a 5\% step change, applied for $250 \mathrm{msec}$ at the voltage reference of machine \#1. This test is activated by opening the timer controlling the voltage reference of machine \#1. All signals show undamped oscillations leading to instability without PSS application. With (d $\omega$-PSS) the responses in Fig. (12), show damped oscillation leading to system stability after $2.0 \mathrm{sec}$ from the disturbance start. Most of the significant variables such as the angle delta, the machine speed deviation, the terminal voltage, the excitation voltage, acceleration power, and the tie-line power are plotted in Fig. (12). 


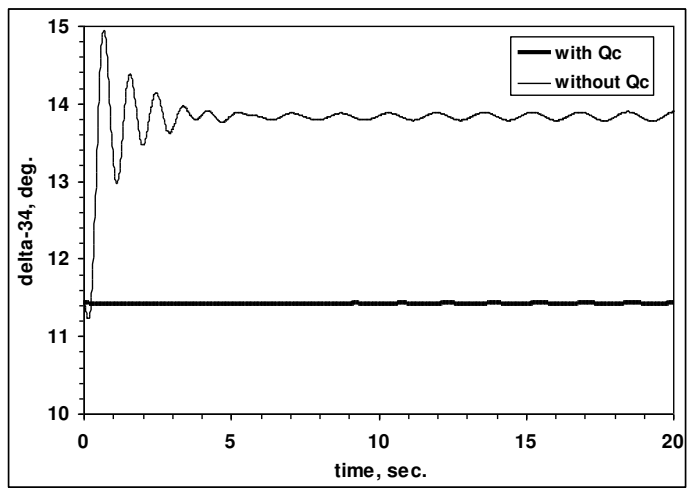

(a)

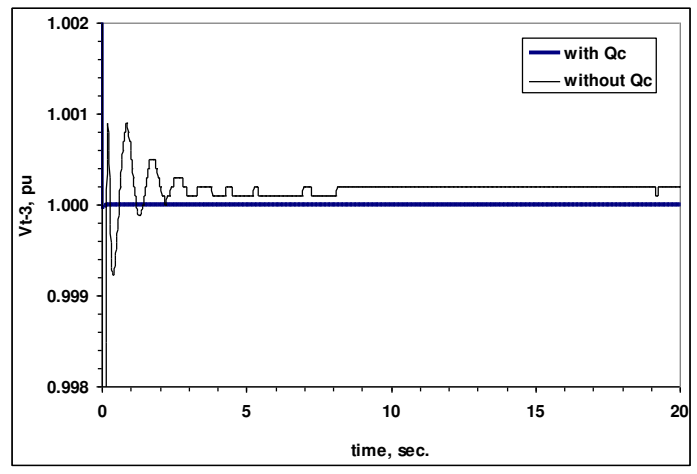

(c)

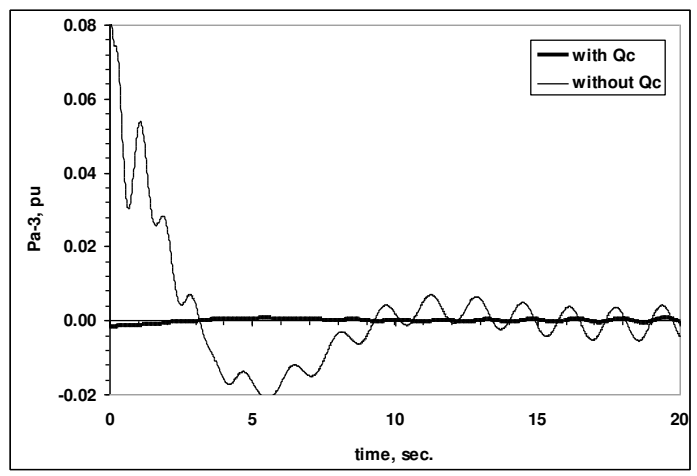

(e)

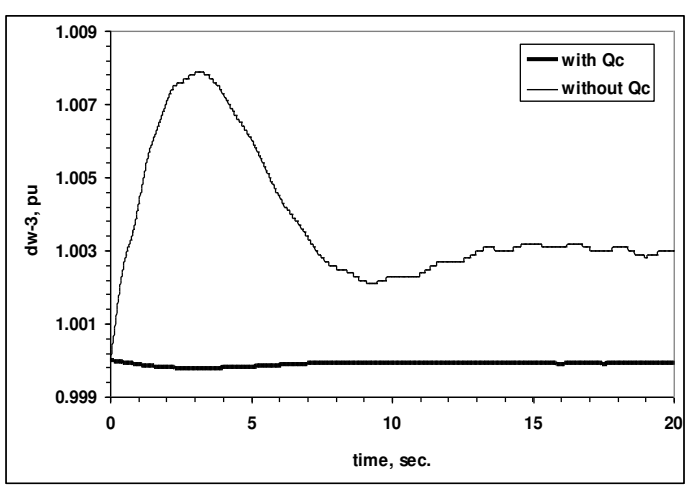

(b)

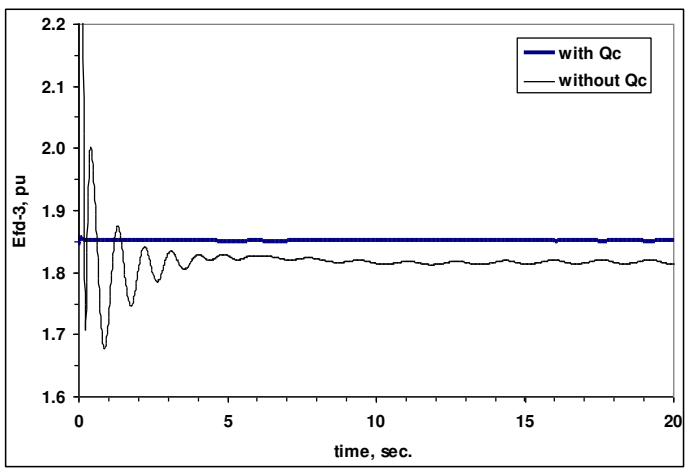

(d)

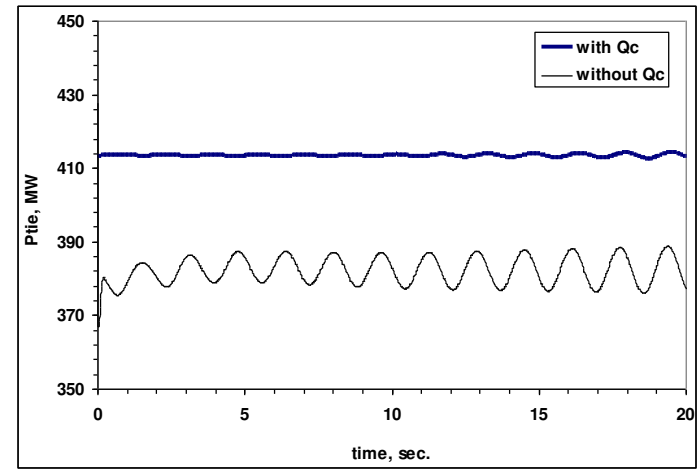

(f)

Fig. (11) Load voltage profile with and without reactive power compensation $\left(\mathrm{Q}_{\mathrm{C}}\right)$
(a) Angle delta $\delta-34$ in (deg.)
(c) Terminal voltage Vt-3 in (pu)
(e) Acceleration power $\mathrm{P}_{\mathrm{a}}-3$ in $(\mathrm{pu})$

(b) Speed devation d $\omega-3$ in (p.u)

(d) Exciter voltage $\mathrm{E}_{\mathrm{fd}}-3$ in $(\mathrm{pu})$

(f) Tie-line power $\mathrm{P}_{\text {tie }} 1-2$ in $(\mathrm{MW})$ 


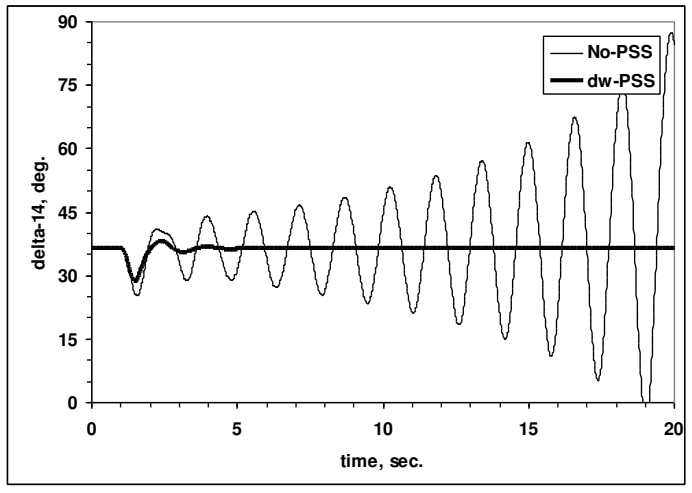

(a)

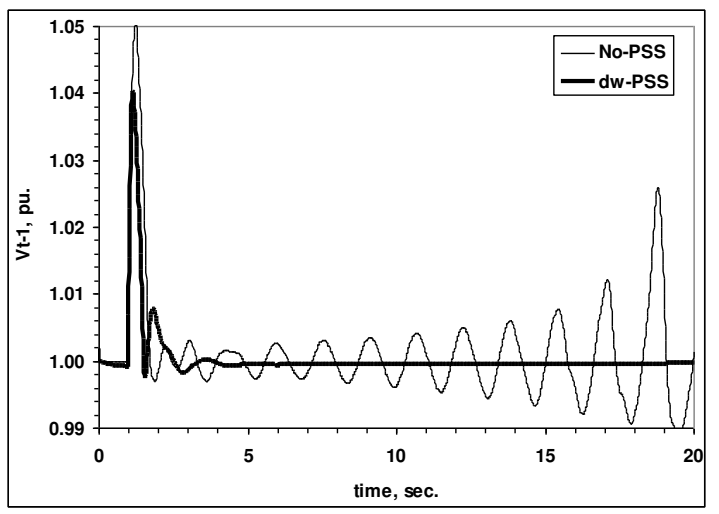

(c)

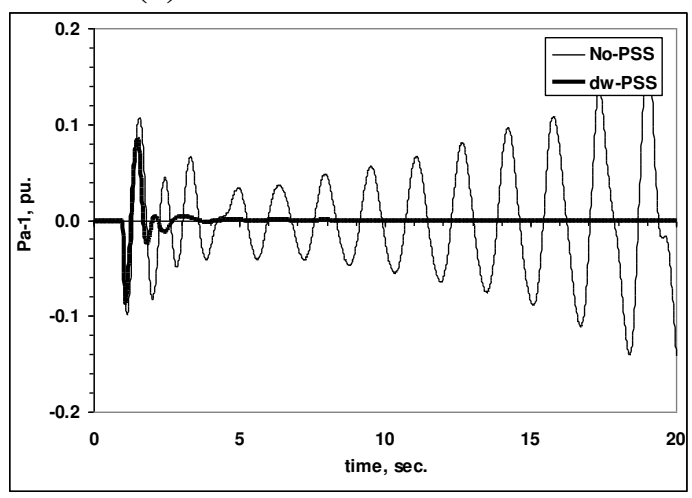

(e)

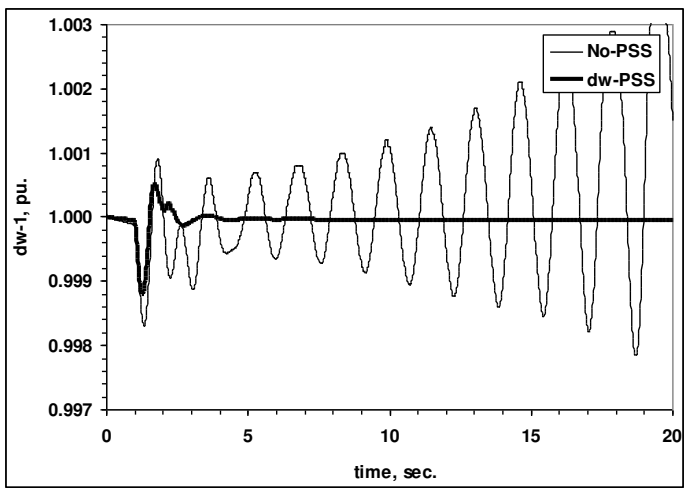

(b)

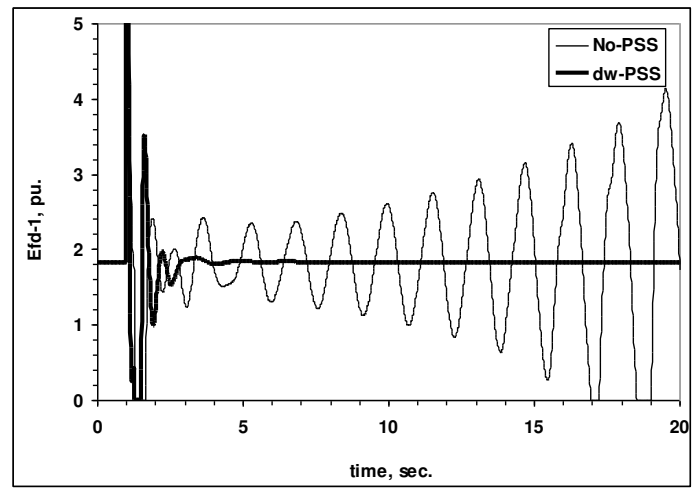

(d)

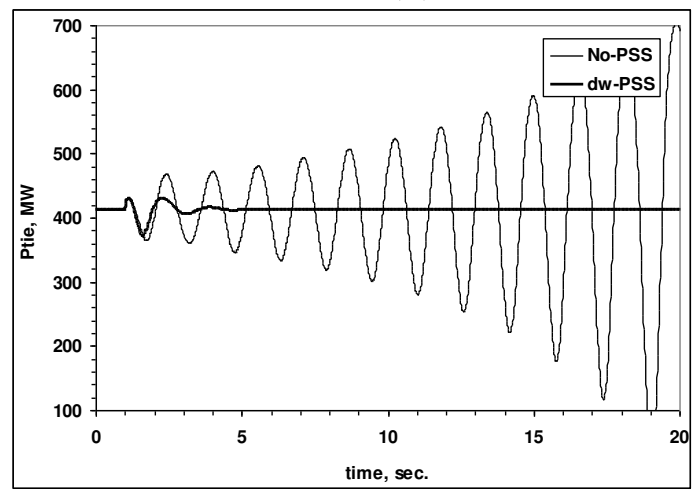

(f)

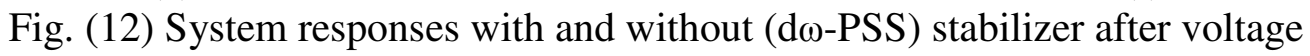
reference disturbance on machine \#1 for $250 \mathrm{msec}$.
(a) Angle delta $\delta$-14 in (deg.)
(b) Speed devation d $\omega-1$ in (p.u)
(c) Terminal voltage Vt-1 in (pu)
(d) Exciter voltage $\mathrm{E}_{\mathrm{fd}}-1$ in (pu)
(e) Acceleration power $\mathrm{P}_{\mathrm{a}}-1$ in (pu)
(f) Tie-line power $\mathrm{P}_{\text {tie }} 1-2$ in (MW) 
If one of the two tie-lines is opened, it is possible to achieve another steady-state stable equilibrium point with the same generation and load patterns. This is called a post-contingency network, easy to initialize using the machine and the load-flow initialization. The network responses after the same $5 \%$ step variation, applied for $200 \mathrm{msec}$ is shown in Fig. (12). System variables responses with and without $\left(\mathrm{dP}_{\mathrm{a}}-\mathrm{PSS}\right)$ after that disturbance are shown in Fig. (13). All signals show undamped oscillations leading to instability in the case of without PSS. Noting that with $\left(\mathrm{dP}_{\mathrm{a}}-\mathrm{PSS}\right)$, and at all disturbances damped oscillation are recorded which has lead to stability after 4.0 seconds from the disturbance application.

\subsection{Effects of system variables responses after three-phase fault with line outage disturbance:}

Assessing a conventional PSS performance with small-signals disturbances is not enough. Good performance during large perturbations and good robustness with respect to changing operating conditions are other criteria for deciding PSS's effectiveness. The system responses to a three-phase fault at the mid point of the one transmission lines cleared after $200 \mathrm{msec}$ by these line outage has been simulated with the same above procedure. With only one tie-line, the system has reached a stable operating point in steady-state, although not every conventional PSS is able to ensure a smooth transition into this new highly stressed operating point. System transient responses with and without MB-PSS after the same disturbance are shown in Fig. (14). All responses show undamped oscillations leading to system instability in the case without PSS. With (MB-PSS), all responses show damped oscillations which led to system stability restoration after $3.0 \mathrm{sec}$. from disturbance application instant.

Comparing transient responses with conventional power system stabilizers response and with multi-band power system stabilizer response subsequent to that three phase fault with one line outage disturbance applied for $200 \mathrm{msec}$ are presented in Fig. (15). Once more, the MB-PSS shows better performances and

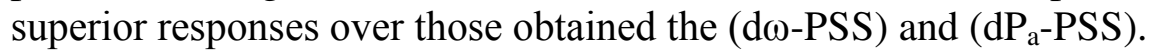

\section{CONCLUSIONS}

a) The MB-PSS and the $\mathrm{d} \omega$-PSS are more effective than the $\mathrm{dP}_{\mathrm{a}}$-PSS. They are able to stabilize the system subsequent to severe disturbances, the $\mathrm{dP}_{\mathrm{a}}$-PSS failed to stabilize the system for the same fault conditions.

b) The d $\omega$-PSS is found to be effective in damping the oscillation of the power transfer between two areas. The closed-loop oscillations frequency of the MB-PSS is lower while those with the d $\omega$-PSS are too slower. They are not sufficient for for recovering the terminal voltage. This is due to the inefficient washout circuits. 


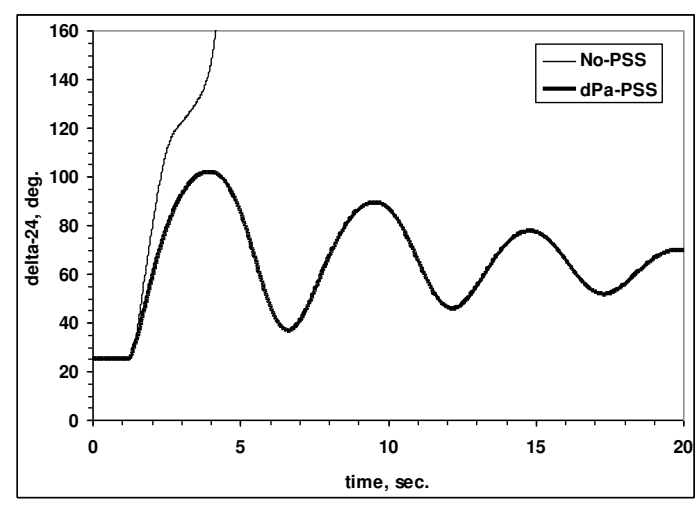

(a)

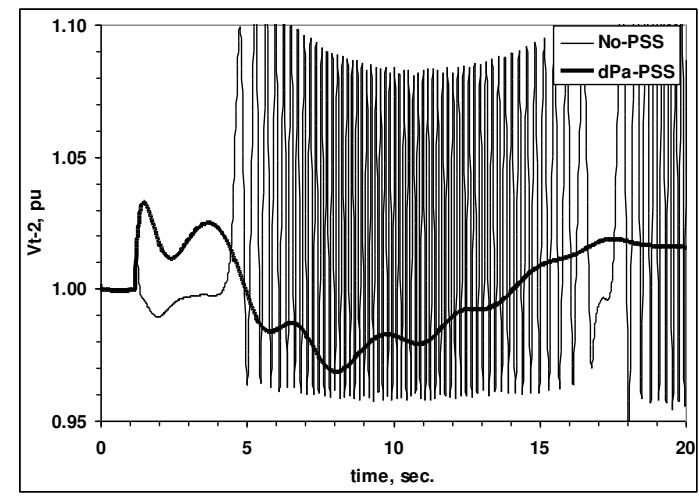

(c)

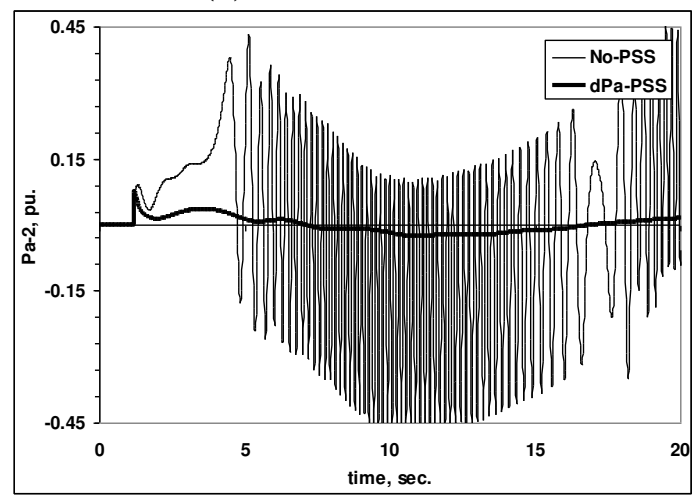

(e)

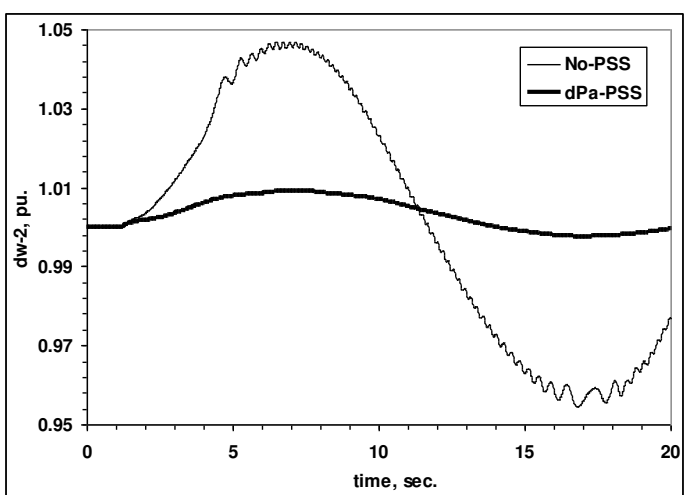

(b)

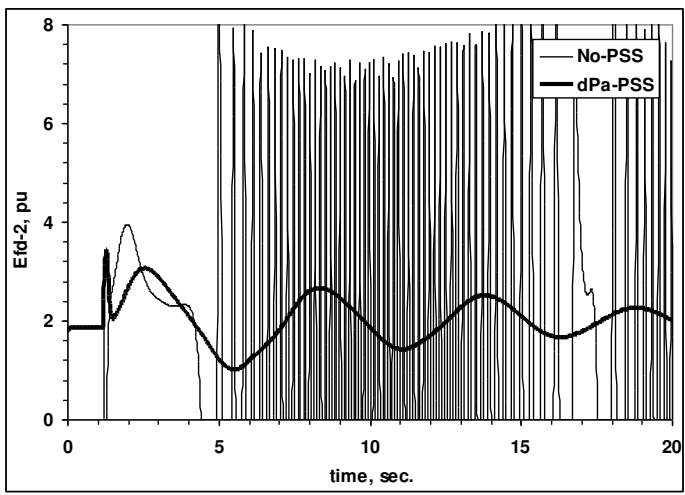

(d)

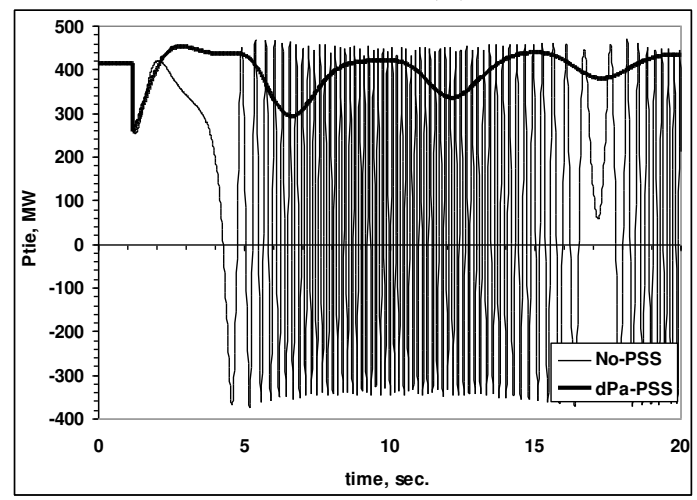

(f)

Fig. (13) System responses with and without ( $\left.\mathrm{dP}_{\mathrm{a}}-\mathrm{PSS}\right)$ stabilizer after one line opening disturbance for $200 \mathrm{msec}$.
(a) Angle delta $\delta-24$ in (deg.)
(c) Terminal voltage Vt-2 in (pu)
(e) Acceleration power $\mathrm{P}_{\mathrm{a}}-2$ in (pu)

(b) Speed devation d $\omega-2$ in (p.u)

(d) Exciter voltage $\mathrm{E}_{\mathrm{fd}}-2$ in (pu)

(f) Tie-line power $\mathrm{P}_{\text {tie }}$ 1-2 in (MW) 


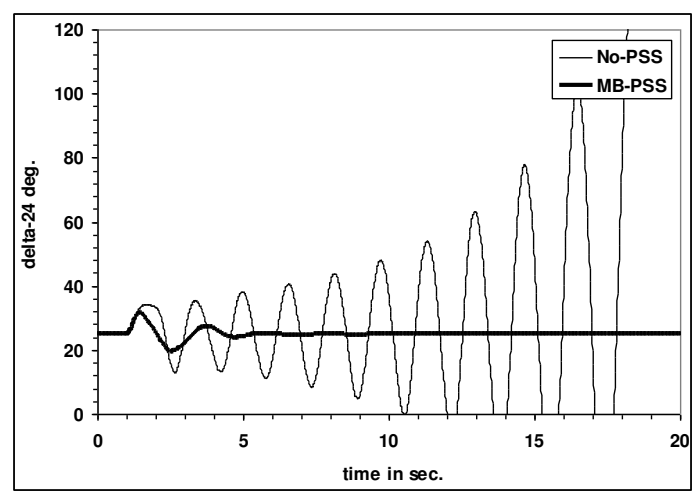

(a)

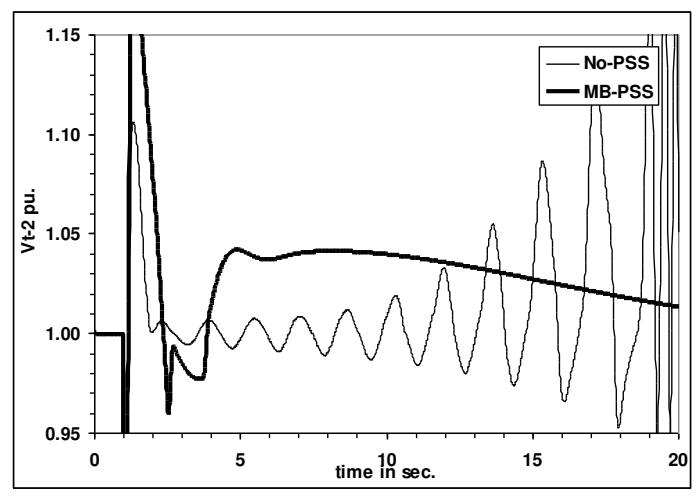

(c)

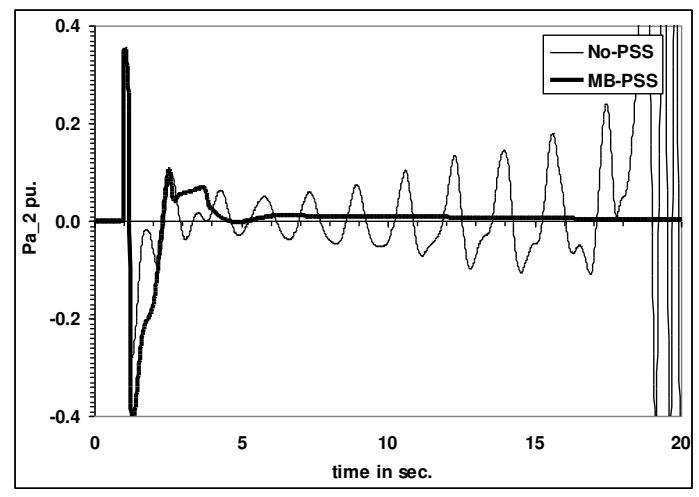

(e)

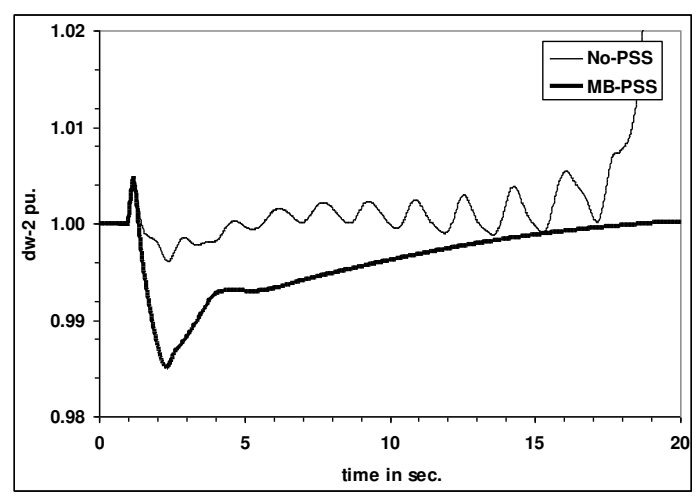

(b)

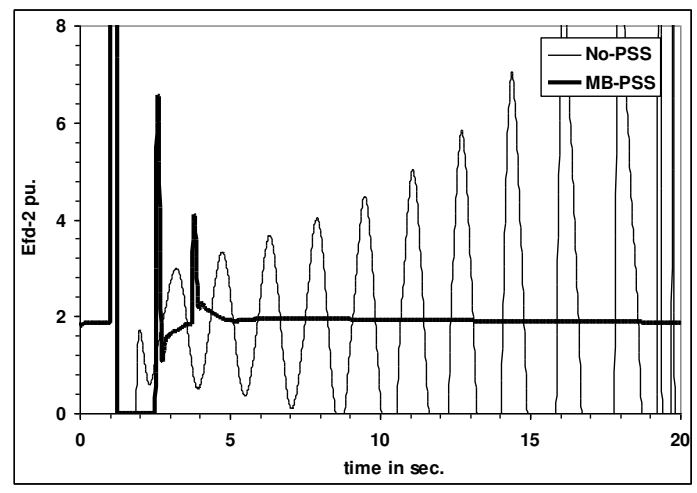

(d)

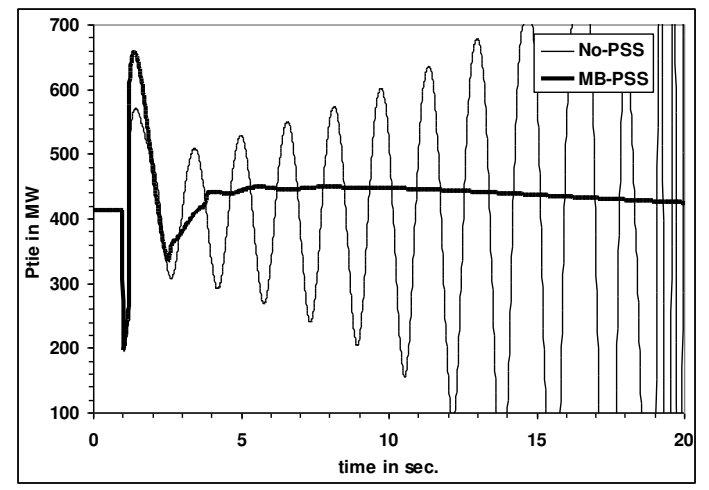

(f)

Fig. (14) System responses with and without (MB-PSS) stabilizer after threephase fault with line outage disturbance for $200 \mathrm{msec}$.
(a) Angle delta $\delta-24$ in (deg.)
(b) Speed devation d $\omega-2$ in (p.u)
(c) Terminal voltage $\mathrm{Vt}-2$ in (pu)
(d) Exciter voltage $\mathrm{E}_{\mathrm{fd}}-2$ in (pu)
(e) Acceleration power $\mathrm{P}_{\mathrm{a}}-2$ in (pu)
(f) Tie-line power $\mathrm{P}_{\text {tie }}$ 1-2 in (MW) 


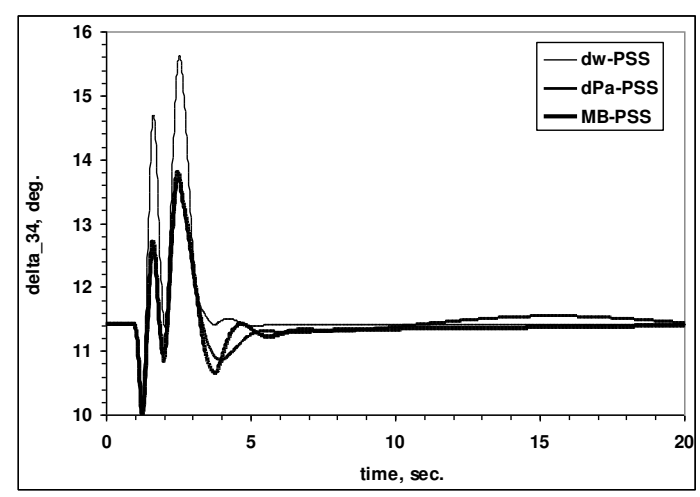

(a)

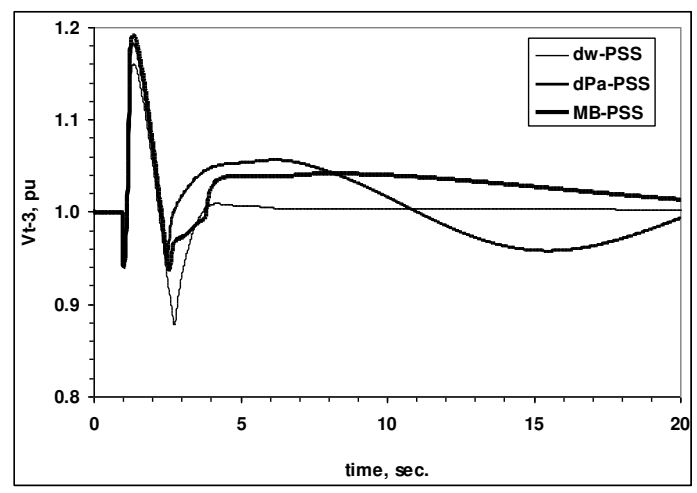

(c)

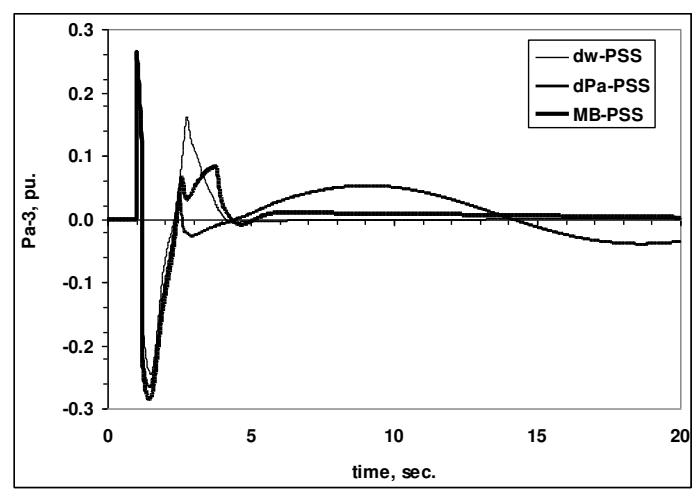

(e)

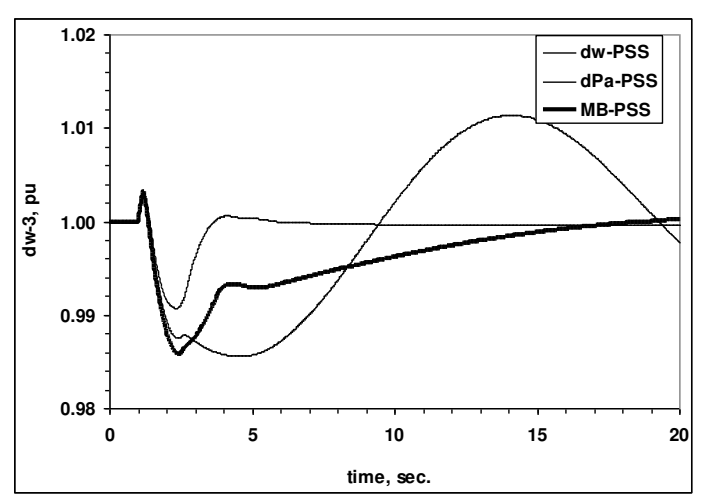

(b)

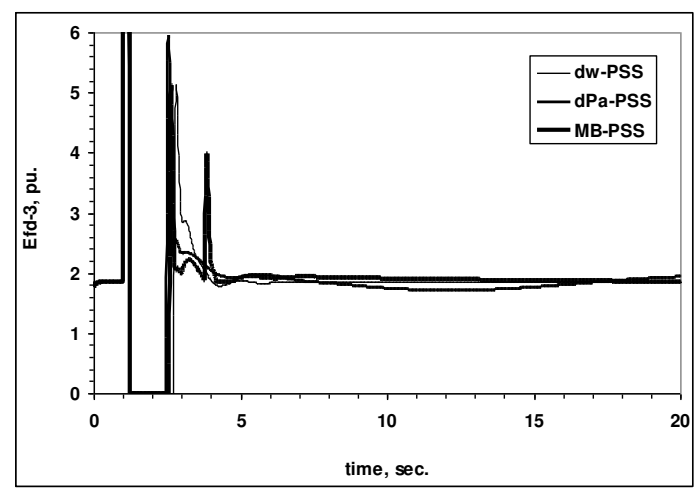

(d)

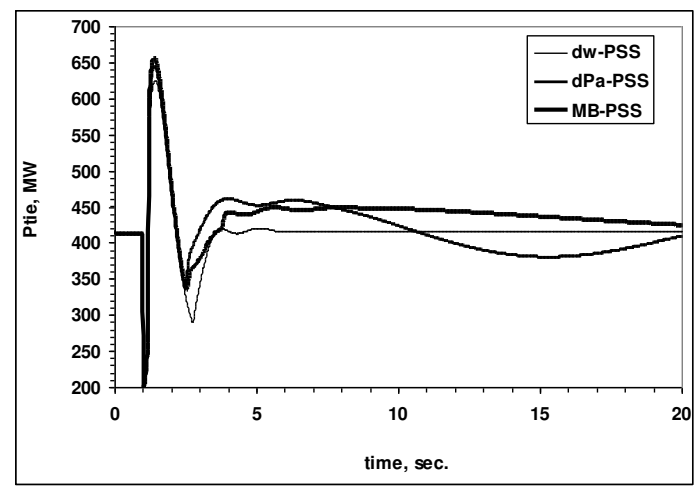

(f)

Fig. (15) Comparative responses with $\mathrm{d} \omega$-PSS, $\mathrm{dP}_{\mathrm{a}}-\mathrm{PSS}$, and MB-PSS stabilizer after three-phase fault followed by a line outage disturbance for $200 \mathrm{msec}$.
(a) Angle delta $\delta$-34 in (deg.)
(b) Speed devation d $\omega-3$ in (p.u)
(c) Terminal voltage Vt-3 in (pu)
(d) Exciter voltage $\mathrm{E}_{\mathrm{fd}}-3$ in $(\mathrm{pu})$
(e) Acceleration power $\mathrm{P}_{a}-3$ in (pu)
(f) Tie-line power $\mathrm{P}_{\text {tie }}$ 1-2 in (MW) 
c) The MB-PSS is superior than the other two PSS's in providing significant more damping to all modes of oscillation, as its structure is based on multiple stages with three separate bands. Its will be then able to damp effectively the low, intermediate, and high-frequency modes of oscillations.

d) The MB-PSS signal can modulate the set point of the generator voltage regulator so as to improve damping of the system electromechanical oscillations.

e) The MB-PSS can be adjusted independently through the three gains $K_{E}, K_{I}$, and $\mathrm{K}_{\mathrm{H}}$. Only six parameters are required, to be calculated.

f) The MB-PSS is able to use all the flexibility in its building structure to achieve nontrivial controller schemes and to tackle even the most constrained problem.

\section{REFERENCES}

[1] Kundur, P., "Power System Stability and Control”, McGraw-Hill, 1994.

[2] Saadat, H., "Power System Analysis", McGraw-Hill, 1999.

[3] El-Sadek M. Z., "Power System Control", Muchtar press- AssiutEgypt-2004.

[4] "IEEE Recommended Practice for Excitation System Models for Power System Stability Studies", IEEE St. 421.5-2002.

[5] Kamwa, I., et al., "Experience with Computer-Aided Graphical Analysis of Sudden-Short-Circuit Oscillograms of Large Synchronous Machines," IEEE Transactions on Energy Conversion, Vol. 10, No. 3, September 1995.

[6] Ali M. Yousef, and Mansour A. Mohamed, "Multimachine Power System Stabilizer Based On Efficient Two-Layered Fuzzy Logic Controller", Transaction on Engineering, Computing and Technology, Vol. 3, Dec. 2004, 1305-5313.

[7] IEEE Subsynchronous Resonance Working Group, "Second Benchmark Model for Computer Simulation of Subsynchronous Resonance," IEEE Transactions on Power Apparatus and Systems, Vol. PAS-104, No. 5, 1985, pp. 1057-1066.

[8] "Recommended Practice for Excitation System Models for Power System Stability Studies", IEEE Standard 421.5-1992, August, 1992.

[9] Klein, Rogers, Moorty and Kundur: "Analytical Investigation of Factors Influencing PSS Performance," IEEE Transactions on Energy Conversion, Vol. 7, No 3, September 1992, pp.382-390.

[10] A. Heniche, I. Kamwa, and R. Grondin, "Torsional-Mode Identification for Turbogenerators with Application to PSS Tuning", IPST'05 in Montreal, Canada on June 19-23, 2005. 


\section{APPENDICES}

Appendix A: 1- Multi-Band-Power System Stabilizer (MB-PSS) Simplified Settings Mode [4]:

$\mathrm{K}=1, \mathrm{~F}_{\mathrm{B}}=0.2 \mathrm{~Hz}, \mathrm{~K}_{\mathrm{E}}=20, \mathrm{~F}_{\mathrm{I}}=0.9 \mathrm{~Hz}, \mathrm{~K}_{\mathrm{I}}=25, \mathrm{~F}_{\mathrm{H}}=12 \mathrm{~Hz}, \mathrm{~K}_{\mathrm{H}}=145$,

$\mathrm{V}_{\text {Lmax }}=0.075, \mathrm{~V}_{\text {Imax }}=0.15, \mathrm{~V}_{\text {Hmax }}=0.15, \mathrm{~V}_{\text {Smax }}=0.15 \mathrm{pu}$

Mode [4]:

2- Multi-Band-Power System Stabilizer (MB-PSS) Detailed Settings

$\mathrm{K}_{\mathrm{B} 1}=66, \mathrm{~K}_{\mathrm{B} 2}=66, \mathrm{~K}_{\mathrm{B}}=9.4$

$\left[\mathrm{T}_{\mathrm{B} 1} \mathrm{~T}_{\mathrm{B} 2} \mathrm{~T}_{\mathrm{B} 3} \mathrm{~T}_{\mathrm{B} 4} \mathrm{~T}_{\mathrm{B} 5} \mathrm{~T}_{\mathrm{B} 6} \mathrm{~T}_{\mathrm{B} 7} \mathrm{~T}_{\mathrm{B} 8} \mathrm{~T}_{\mathrm{B} 9} \mathrm{~T}_{\mathrm{B} 10} \mathrm{~T}_{\mathrm{B} 11} \mathrm{~T}_{\mathrm{B} 12} \mathrm{~K}_{\mathrm{B} 11} \mathrm{~K}_{\mathrm{B} 17}\right]=$ $[1.667,2,0,0,0,0,2,2.4,0,0,0,0,1,1] \mathrm{Hz}$

$\mathrm{K}_{\mathrm{I} 1}=66, \mathrm{~K}_{\mathrm{I} 2}=66, \mathrm{~K}_{\mathrm{I}}=47.6$

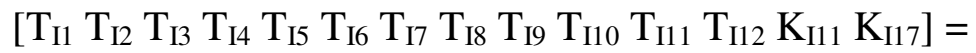

$[1,1,0.25,0.3,0,0,1,1,0.3,0.36,0,0,0,0] \mathrm{Hz}$

$\mathrm{K}_{\mathrm{H} 1}=66, \mathrm{~K}_{\mathrm{H} 2}=66, \mathrm{~K}_{\mathrm{H}}=233$

$\left[\mathrm{T}_{\mathrm{H} 1} \mathrm{~T}_{\mathrm{H} 2} \mathrm{~T}_{\mathrm{H} 3} \mathrm{~T}_{\mathrm{H} 4} \mathrm{~T}_{\mathrm{H} 5} \mathrm{~T}_{\mathrm{H} 6} \mathrm{~T}_{\mathrm{H} 7} \mathrm{~T}_{\mathrm{H} 8} \mathrm{~T}_{\mathrm{H} 9} \mathrm{~T}_{\mathrm{H} 10} \mathrm{~T}_{\mathrm{H} 11} \mathrm{~T}_{\mathrm{H} 12} \mathrm{~K}_{\mathrm{H} 11} \mathrm{~K}_{\mathrm{H} 17}\right]=$ $[0.01,0.012,0,0,0,0,0.012,0.0144,0,0,0,0,1,1] \mathrm{Hz}$

$\mathrm{V}_{\text {Lmax }}=0.075, \mathrm{~V}_{\text {Imax }}=0.15, \mathrm{~V}_{\text {Hmax }}=0.15, \mathrm{~V}_{\mathrm{Smax}}=0.15 \mathrm{pu}$

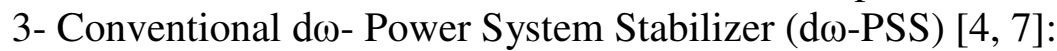

$\mathrm{K}=30, \mathrm{~T}_{\mathrm{w}}=10, \mathrm{~T}_{1 \mathrm{n}}=0.05, \mathrm{~T}_{1 \mathrm{~d}}=0.02, \mathrm{~T}_{2 \mathrm{n}}=3, \mathrm{~T}_{2 \mathrm{~d}}=5.4 \mathrm{sec}, \mathrm{V}_{\mathrm{smin}}=-0.15$, $\mathrm{V}_{\mathrm{smax}}=0.15 \mathrm{pu}$

4- Conventional $\mathrm{dP}_{\mathrm{a}}$ - Power System Stabilizer ( $\left.\mathrm{dP}_{\mathrm{a}}-\mathrm{PSS}\right)[4,7]$ :

$\mathrm{K}=3.125, \mathrm{~T}_{\mathrm{w}}=1, \mathrm{~T}_{1 \mathrm{n}}=0.06, \mathrm{~T}_{1 \mathrm{~d}}=1.0, \mathrm{~T}_{2 \mathrm{n}}=0, \mathrm{~T}_{2 \mathrm{~d}}=0 \mathrm{sec}, \mathrm{V}_{\mathrm{smin}}=-0.15$, $\mathrm{V}_{\mathrm{smax}}=0.15 \mathrm{pu}$

5- Synchronous Generator [1, 4]:

$\mathrm{X}_{\mathrm{d}}=1.8, \mathrm{X}_{\mathrm{d}}{ }^{\prime}=0.3, \mathrm{X}_{\mathrm{d}}{ }^{\prime \prime}=0.25, \mathrm{X}_{\mathrm{q}}=1.7, \mathrm{X}_{\mathrm{q}}{ }^{\prime}=0.55, \mathrm{X}_{\mathrm{q}}{ }^{\prime \prime}=0.25, \mathrm{X}_{\mathrm{l}}=0.2 \mathrm{pu}$,

$\mathrm{R}_{\mathrm{s}}=0.0025 \mathrm{pu}, \mathrm{T}_{\mathrm{do}}{ }^{\prime}=8, \mathrm{~T}_{\mathrm{do}}{ }^{\prime \prime}=0.03, \mathrm{~T}_{\mathrm{qo}}{ }^{\prime}=0.4, \mathrm{~T}_{\mathrm{qo}}{ }^{\prime \prime}=0.05, \mathrm{H}=6.5, \mathrm{p}=4$

6- Excitation System [1, 3]:

$\mathrm{T}_{\mathrm{r}}=0.02, \mathrm{~K}_{\mathrm{a}}=300, \mathrm{~T}_{\mathrm{a}}=0.001, \mathrm{~K}_{\mathrm{e}}=1, \mathrm{~T}_{\mathrm{e}}=0, \mathrm{~T}_{\mathrm{b}}=0, \mathrm{~T}_{\mathrm{c}}=0, \mathrm{~K}_{\mathrm{f}}=0.001, \mathrm{~T}_{\mathrm{f}}=0.1$, $\mathrm{E}_{\mathrm{fmin}}=-11.5, \mathrm{E}_{\mathrm{fmax}}=11.5$

7- Steam Turbine and Governor [4, 7]:

$\mathrm{K}_{\mathrm{p}}=1, \mathrm{R}_{\mathrm{p}}=0.05, \mathrm{D}_{\mathrm{z}}=0, \mathrm{~T}_{\mathrm{sr}}=0.001, \mathrm{~T}_{\mathrm{sm}}=0.15, \mathrm{~V}_{\mathrm{gmin}}=-0.1, \mathrm{~V}_{\mathrm{gmax}}=0.1 \mathrm{pu} / \mathrm{s}$, $\mathrm{g}_{\min }=0, \mathrm{~g}_{\max }=4.496 \mathrm{pu}$,

$\mathrm{T}_{2}=0, \mathrm{~T}_{3}=10, \mathrm{~T}_{4}=3.3, \mathrm{~T}_{5}=0.5$, and $\mathrm{F}_{2}=0.5, \mathrm{~F}_{3}=0.5, \mathrm{~F}_{4}=0, \mathrm{~F}_{5}=0$,

$\mathrm{H}_{2}=1.5498, \mathrm{H}_{3}=0.24897, \mathrm{H}_{4}=0, \mathrm{H}_{5}=0$, and $\mathrm{K}_{12}=83.47, \mathrm{~K}_{23}=42.702$, $\mathrm{K}_{34}=0, \mathrm{~K}_{45}=0 \mathrm{pu} / \mathrm{rad}$,

$\mathrm{D}_{2}=2.4832, \mathrm{D}_{3}=0.4, \mathrm{D}_{4}=0, \mathrm{D}_{5}=0 \mathrm{pu}$ torque/pu speed deviation

Appendix B: Synchronous Generator Model [7]:

$$
V_{d}=R_{s} i_{d}+\frac{d \varphi_{d}}{d t}-\omega_{R} \varphi_{q}, \text { and } V_{q}=R_{s} i_{q}+\frac{d \varphi_{q}}{d t}+\omega_{R} \varphi_{d}
$$




$$
\begin{aligned}
& V_{f d}^{\prime}=R_{f d}^{\prime} i_{f d}^{\prime}+\frac{d \varphi_{f d}^{\prime}}{d t}, \text { and } V_{k d}^{\prime}=R_{k d}^{\prime} i_{k d}^{\prime}+\frac{d \varphi_{k d}^{\prime}}{d t} \\
& V_{k q 1}^{\prime}=R_{k q 1}^{\prime} i_{k q 1}^{\prime}+\frac{d \varphi_{k q 1}^{\prime}}{d t}, \text { and } V_{k q 2}^{\prime}=R_{k q 2}^{\prime} i_{k q 2}^{\prime}+\frac{d \varphi_{k q 2}^{\prime}}{d t} \\
& \varphi_{d}=L_{d} i_{d}+L_{m d}\left(i_{f d}^{\prime}+i_{k d}^{\prime}\right), \text { and } \varphi_{q}=L_{q} i_{q}+L_{m q} i_{k q} \\
& \varphi_{f d}^{\prime}=L_{f d}^{\prime} i_{f d}^{\prime}+L_{m d}\left(i_{d}+i_{k d}^{\prime}\right), \text { and } \varphi_{k d}^{\prime}=L_{k d}^{\prime} i_{k d}^{\prime}+L_{m d}\left(i_{d}+i_{f d}^{\prime}\right) \\
& \varphi_{k q 1}^{\prime}=L_{k q 1}^{\prime} i_{k q 1}^{\prime}+L_{m q} i_{q}, \text { and } \varphi_{k q 2}^{\prime}=L_{k q 2}^{\prime} i_{k q 2}^{\prime}+L_{m q} i_{q}
\end{aligned}
$$

\section{منظم متعدد الروابط لاتزان نظم القوى باستخدام السيميولتك}

يتتاول البحث دراسة منظم متعدد الروابط لاتزان نظم القوى للحصول على مرحلة الاستقرار و ضمان

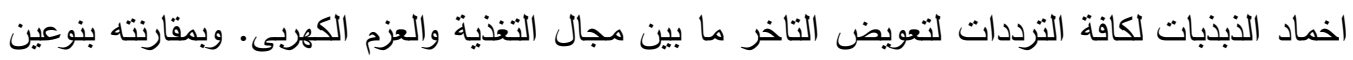
من نظم اتزان القوى العادية لاخماد تذبذبات العضو الدوار للالات المتزامنة بواسطة التحكم فى تغذيتها اثثاء الاضطرابات الناتجة فى نظم القوى. اداء المنظم متعدد الروابط المستخدم فى تحسين استقرار نظم

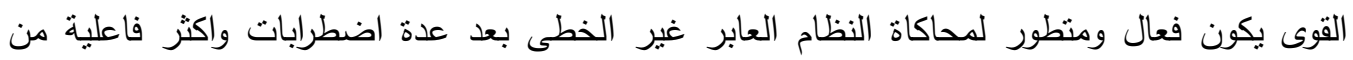

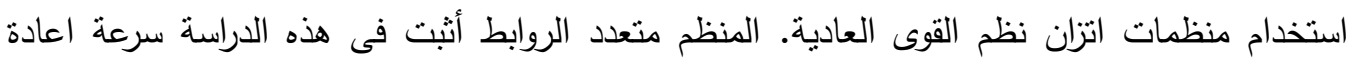
استقرار الثبكة بعد الاضطرابات الختلفة. واثثبت فعاليته عن المنظمات الثقليدية المعروفة المغذاه باشارة من التغير فى سرعة الماكينات أو باشارة من التغير فى القدرة المعجلة للحركة فى الماكينات التزامنية. 